\title{
Giant hyperostosis after sphenoid ridge en plaque meningioma removal
}

\author{
Danil Adam ${ }^{1}$, Toma Papacocea ${ }^{1}$, Ioana Hornea ${ }^{2}$, \\ Cristiana Moisescu ${ }^{2}$
}

1University of Medicine and Pharmacy Carol Davila, Bucharest

2“Saint Pantelimon” Emergency Hospital, Bucharest

\begin{abstract}
Meningioma is in most cases a benign tumor of the central nervous system with two growth patterns: en masse and en plaque. Hyperostosis is associated in $13-49$ $\%$ of the cases with en plaque meningioma. We describe the case of a 47 years old woman with meningotelial sphenoid ridge meningioma which was totally removed. At the first admission she presented with no neurological deficits, seizures and a mild right exophthalmos. This had an indolent growth. After 10 years, the patient was readmitted for headache, blurred vision and right exophthalmos. Skull X-rays and brain MRI revealed an important thickening of the right superior orbit wall and sphenoid ridge. She underwent a new surgery. There was no intradural tumor found. Instead, bones of the superior and lateral right orbit walls were very hiperostotic. A hole of $3 / 2 \mathrm{~cm}$ in the right superior orbital wall was drilled and the orbital cavity was decompressed. In the postoperative period, the symptoms were remitted and the exophthalmos reduced. We discuss the causes and management of hyperostosis associated with meningiomas.
\end{abstract}

Key words: meningioma, hyperostosis, bone invasion.

\section{Introduction}

Meningioma is a primary tumor of the central nervous system which accounts for about $20 \%$ of all intracranial tumors, more than $35 \%$ of primary brain and central nervous system tumors and $53.8 \%$ of nonmalignant brain and CNS tumors (1).

Nomenclature of intracranial meningiomas refers to their location, pathological features and some growth characteristics. Cushing and Eisenhardt coined the terms meningioma en masse and en plaque (2).

Meningiomas en plaque represent $2-4 \%$ of intracranial meningiomas. They are associated with hyperostosis in $13-49 \%$ of the cases $(3,4)$.

The association of meningiomas with adjacent bone hyperostosis was discussed for the first time in 1903 by Brissaud and Lererbaullet (5).

We report the case of a patient with 
sphenoid ridge meningioma with massive hyperostosis extended to the orbit and floor of the middle cranial fossa.

\section{Case report}

A 47 years old woman with right sphenoid ridge tumor was operated in 2003. Tumor pathology was meningotelial meningioma.

At that time, the patient presented a mild right exophthalmos.

In the next 10 postoperative years she was under neurologist care for seizures and Parkinson disease. Right exophthalmos had an indolent growth.

The patient was again admitted in our Neurosurgical Department in 2014 for headache, exophthalmos and blurred vision at the right eye.

According to the ophthalmological examination, right exophthalmos had $29 \mathrm{~mm}$ in axial plane, was irreducible, extraocular eye movements were normal and visual acuity was 1/1. She had no neurological deficits. She presented a swelling of the zygomatic region.

Skull X-ray and axial T2-weighted and T1weighted MRI images showed hyperostosis of the right sphenoid ridge and superior and lateral orbital bones extended to the middle cranial fossa (Figures 1, 2, 3).

The patient underwent a new surgery through the same pterional approach. An intradural tumor was not found but the orbital roof presented multiple osseous spiculi. With the aid of a drill, a hole was created in the superior orbital wall with the depth of $3 \mathrm{~cm}$, which was enlarged until $3 / 2 \mathrm{~cm}$, through which the periorbit herniated (Figure 4). The optic canal was not uncovered. Dura mater was closed with autologous fascia lata graft. The bone flap was replaced.

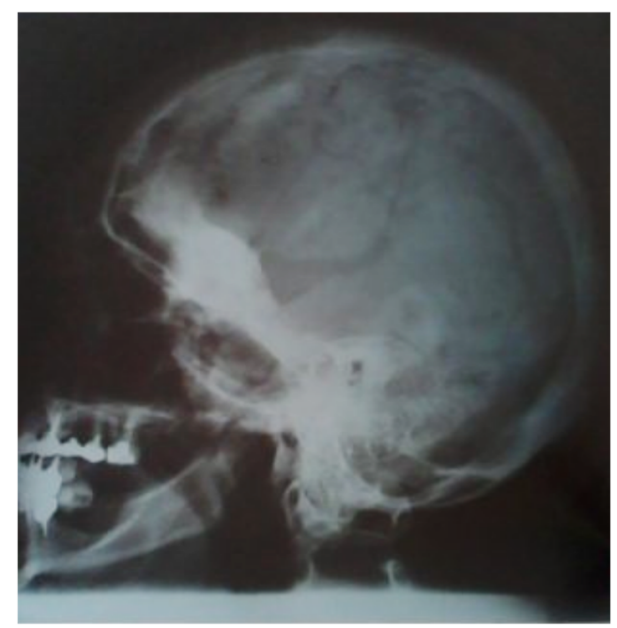

Figure 1 - Preoperative skull X-ray showing hyperostosis of the right sphenoid ridge and lateral orbital walls extended to the middle cranial fossa (highlighted by dotted circle)

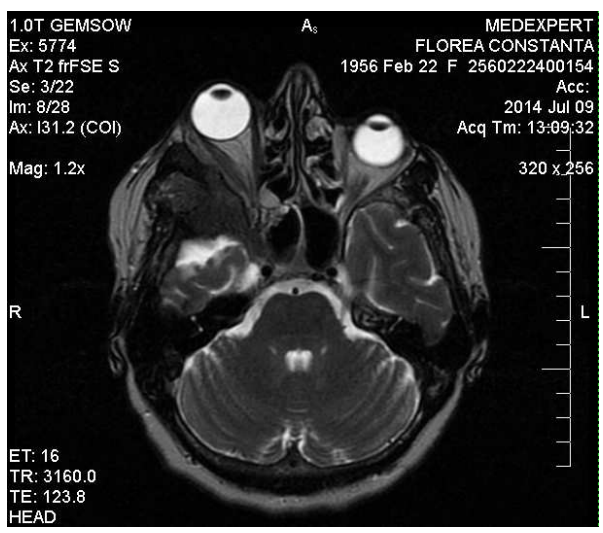

Figure 2 


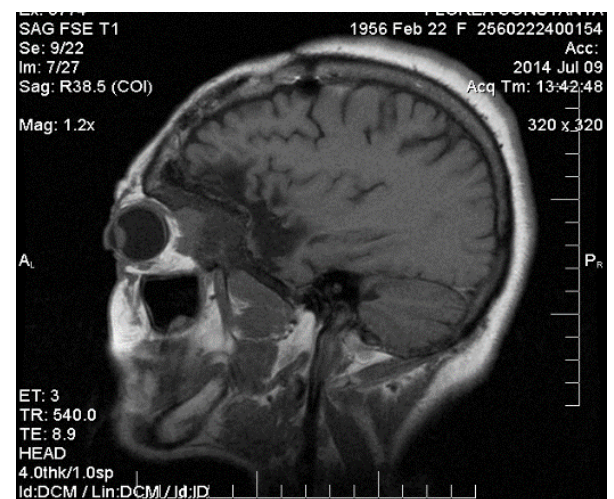

Figure 3

Figures 1, 2 - Preoperative axial and sagittal cerebral MRI showing important hyperostosis of the right sphenoid ridge and lateral orbital walls extended to the right anterior temporal lobe (highlighted by red arrows)

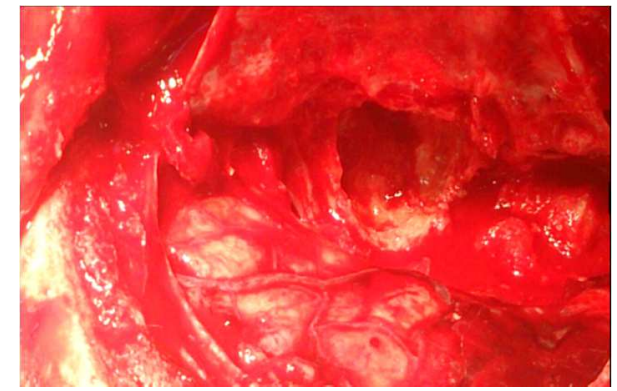

Figure 4 - Intraoperative image showing a hole created with the aid of a drill in the superior orbital wall $3 \mathrm{~cm}$ deep, enlarged until $3 / 2 \mathrm{~cm}$ through which the periorbit herniated (highlighted by dotted circle)

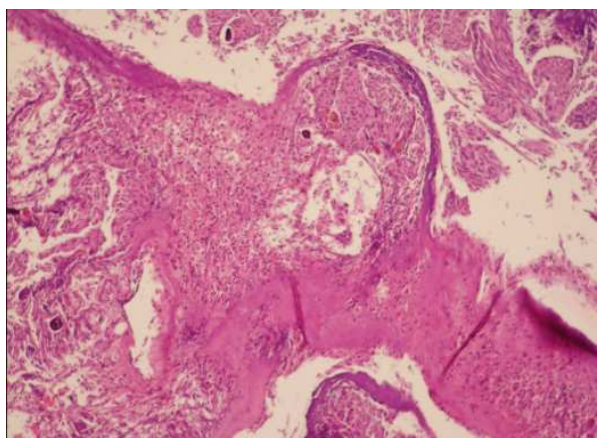

Figure 5 - Morpho-pathological aspects of tumor: monomorphic spindle cells with central round/ oval nuclei of meningothelial meningioma with bone infiltration (arrow)

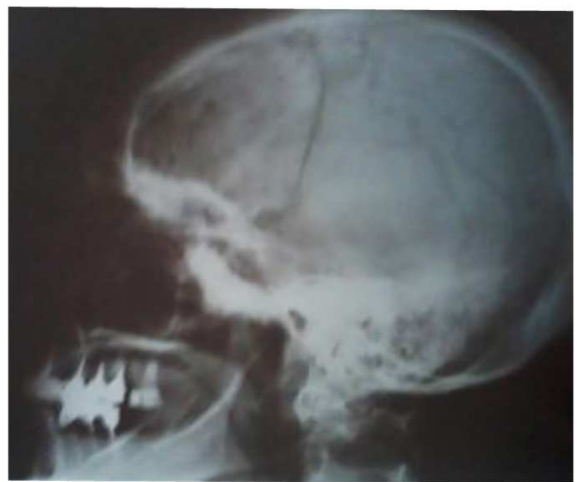

Figure 6 - Postoperative skull X-ray showing radiolucency (highlighted by dotted circle) in the superior orbital wall instead of hyperostosis

Postoperative recovery was uneventful, with immediate $5 \mathrm{~mm}$ reduction of ptosis, disappearance of headache and of blurred vision. Pathological examination revealed invasion of the bone with meningotelial cells (Figure 5).

Skull X-ray showed radiolucency in the superior orbital wall instead of hyperostosis (Figure 6).

At the 6 months follow up the patient is without symptoms and exophthalmos remained stable.

\section{Discussions}

Intracranial meniongiomas develop from the arachnoid villi. In their development, they can form globular tumor masses or they can diffuse along the dura mater, creating what Cushing and Eisenhardt (2) have termed en plaque meningiomas. Even though they do not exceed the leptomeninges, at the base of implantation the dura mater appears thickened and infiltrated with tumor cells. A sign associated to meningiomas is 
hyperostosis, which has a variable incidence and is more frequently observed in en plaque meningiomas.

There were issued several hypothesis regarding the cause of hyperostosis. In 1934, Echlin suggested that the bone adjacent to the tumor is infiltrated with tumor cells (6). In 1937, Globus stated that neoplastic cells invade the bone through the Haversian system (7). In order to avoid recurrence, other authors recommended excision of the tumor and of the hiperostotic bone $(4,8)$. Simpson showed that in case of grade I resection (total removal of the tumor, of the dural attachment and of the invaded bone), the 10 years recurrence rate is $9 \%$, compared to $40 \%$ in the case of subtotal tumor resection (8).

Recent histopathological studies demostrated bone infiltrated by tumor in the hiperostotic area $(9,10)$.

Kim and colab. described, according to the CT aspect, 4 different patterns of hyperostosis in en plaque meningiomas: homogeneous, periostal, diploic and threelayered. They consider that the tumor invasion of the periosteum stimulates the forming of the bone (11).

Others consider that the bone metabolism is hormonally and enzymatically controlled $(12,13)$.

Through recent immunohistochemical studies, Matschke and colab. demonstrated the presence of somatostatin $2 \mathrm{~A}$ receptor in the meningiomas, which can have diagnostic implications. Octreotide scintigraphy, a somatostatin analog, allows visualization of the meningioma and permits differentiating it from schwannoma or scar tissue. This method could be of great use in diagnosing patients with meningiomas without hyperostosis in which histopathological studies show bone invasion.

Timirgaz and colab. published the case of en plaque meningioma of the sphenoid ridge with easily resectable "soft" hyperostosis (15).

The invasion of the sphenoid ridge and of the orbital walls by an en plaque meningioma may produce their osteolysis and easy decompression of the orbit (16).

From the therapeutic point of view, the purpose of surgery is total removal of the tumor and aggressive resection of hiperostotic bone $(17,18)$. Regarding en plaque meningioma developed at the cranial base, this objective is not possible.

Piepper and colab. reported a $69 \%$ rate of tumor bone invasion in case of skull base meningiomas (19).

Extensive invasion of the orbital bone and middle fossa floor by an en plaque meningioma does not confer the character of histological malignancy.

In the presented case, the hiperostotic superior orbital wall, with a thickness of $3 \mathrm{~cm}$, had a very high density.

Even though there was no intradural tumor regrowth, histopathological studies showed that hiperostotic bone contained tumor cells, having the aspect of meningotelial meningioma.

The total removal of the hiperostotic bone was not possible because of the extension of hyperostosis and infiltrated bone density: the superior and lateral orbit walls, anterior clinoida, medial wall of the sphenoid sinus, the floor of the middle cranial fossa as well as the zygomatic bone. The optic canal 
DOI: 10.2478/romneu-2014-0063

decompression was not performed because of fear of mechanical or thermal damage to the optic nerve.

The preoperative visual acuity was $1 / 1$ and postoperatively it maintained at the same value. The exophthalmos decreased. Blurred vision disappeared.

We consider that orbital decompression and intraorbital pressure reduction were sufficient measures to improve symptoms. A more aggressive resection may have produced optic nerve damage and enophthalmos.

In the case of a less hiperostotic superior orbital wall, we believe that croping and milling it on both sides in order to reduce its thickness followed by restoring it into place, subdurally, without anchoring to adjacent bone structures, would be indicated. Its final position will be influenced by intracranial and intraorbital pressure equalization.

\section{Conclusions}

Intracranial meningiomas are accompanied by ostosis, morphological changes of infiltrated bone, such as hyperostosis or osteomalacia. The case of an en plaque meningioma of sphenoid ridge accompanied by orbital walls and middle cranial fossa floor hyperostosis was presented.

The surgical treatment of en plaque meningioma accompanied by hyperostosis should aim total removal of the tumor, of the infiltrated dura mater and, as far as possible, of the tumor infiltrated bone. Total resection is unfeasible.

\section{References}

1. Quinn T. Ostrom, Haley Gittleman, Paul Farah et al: CBTRUS Statistical Report: Primary Brainand Central Nervous System Tumors Diagnosed in the United States in 2006-2010, Neuro-Oncology, 15 Suppl 2: ii1-ii56, 2013. 2. Cushing H, Eisenhardt L: Meningiomas. Their cassification, regional behaviours, life history and surgical end results. Charles C. Thomas. Springfield, IL, 1938.

3. Cushing H: The cranial hyperostosis produced by meningeal endotheliomas. Arch.Neurol.Psychiatry 8: 139-154, 1922.

4. Binnal J, Thibault A, Brotche J, Born J: Invading meningiomas of the sphenoid ridge. J Neurosurg 53: 587599, 1980.

5. Brissaud, Lererbaullet P: Deux cas d'hemicraniose Rev Neurol 11: 537-540, 1903.

6. Echlin F: Cranial osteomas and hyperostoses produced by meningeal fibroblastomas. Arch Surg 28: 357-405, 1934.

7. Globus JH: The meningiomas. Trans Assoc Res Nerv Ment Dis 16: 210-265, 1937.

8. Simpson D: The recurrence of intracranial meningiomas after surgical treatment. J Neurol Neurosurg Psychiatry 20: 22-39, 1957.

9. Akutsu H, Sagita K, Sonibe M, Matsumura A: Parasagital meningioma en plaque with extracranial extension presenting diffuse massive hyperostosis of the skull. Surg Neurol 61: 165-169, 2004.

10. Gupta SK, Mohindra S, Radotra BD, Klosla VK: Giant calvarial hyperostosis with biparasagittal en plaque meningioma. Neurol India 54: 210-211, 2006.

11. Kim KS, Rogers LF, Goldblatt D: CT features of hiperostosing meningioma en plaque. AJR Am J Roentgenol 49: 1017-1023, 1987.

12. Heick A, Mosdal C, Iorgensen K, Klinken L: Localized cranial hyperostosis of meningioma: a result of neoplastic enzymatic activity? Acta Neurol Scand 87: 243-247, 1993. 13. Oury F, Yardav VK, Wang Y et al: CREB mediates brain serotonin regulation of bone mass through its expression in ventromedial hypothalamic neurons. Genes Dev 24: 2330-2342, 2010.

14. Matschke J, Addo J, Bernreuther C, Zustin J: Osseous chamges in meningioma en plaque. Anticancer research 31: 591-596, 2011. 
15. Timirgaz V, Crihan A: Unele aspecte ale tratamentului chirurgical al meningiomului "en plaque" de aripa sfenoidala cu hiperostoza osoasa care a provocat exoftalmie. Buletinul Academiei de Stiinte a Moldovei. Stiinte Medicale. Chisinau: 3/(22): 83-88, 2009.

16. Jin-UK Baek, Young-Dae Cho, Jae-Chul Yoo: An osteolitic meningioma en plaque of the sphenoid ridge. J Korean Neurosurg. Soc. 43(1): 34-46, 2008.

17. Maroon JC, Kennerdell JS, Vidovich DV: Sphenoorbital craniotomy for meningioma, in Rengachary SS,
Wilkens RH (eds): Neurosurgical Operative Atlas, Park Ridge, AANS, 1993, vol 3, pp 249-257.

18. Maroon JC, Kennerdell JS, Vidovich DV et al: Recurrent spheno-orbital meningioma. J Neurosurg 80: 202-208, 1994.

19. Pieper DR, Al-Mefty O, Hanada Y, Buechner D: Hyperostosis associated with meningioma of the cranial base: Secondary changes of tumor invasion. Neurosurgery 44: 742-747, 1999. 